\section{Comparison of total body irradiation versus non-total body irradiation containing regimens for de novo acute myeloid leukemia in children}

\author{
Christopher E. Dandoy, ${ }^{1,2}$ Stella M. Davies,,${ }^{1,2}$ Kwang Woo Ahn, ${ }^{3}$ Yizeng He, ${ }^{3}$ \\ Anders E. Kolb, ${ }^{4}$ John Levine, ${ }^{5}$ Stephanie Bo-Subait, ${ }^{6}$ Hisham Abdel-Azim, ${ }^{7}$ \\ Neel Bhatt, ${ }^{8}$ Joseph Chewning, ${ }^{9}$ Shahinaz Gadalla, ${ }^{10}$ Nicholas Gloude, ${ }^{11}$ Robert \\ Hayashi, ${ }^{12}$ Nahal R. Lalefar, ${ }^{13}$ Jason Law, ${ }^{14}$ Margaret MacMillan, ${ }^{15}$ Tracy \\ O'Brien, ${ }^{16}$ Timothy Prestidge,${ }^{17}$ Akshay Sharma, ${ }^{18}$ Peter Shaw,${ }^{19}$ Lena \\ Winestone ${ }^{20}$ and Mary Eapen ${ }^{21}$
}

${ }^{1}$ Division of Hematology-Oncology, Cincinnati Children's Hospital Medical Center, Cincinnati, OH, USA; 'Department of Pediatrics, University of Cincinnati, Cincinnati, $\mathrm{OH}$, USA; ${ }^{3}$ Division of Biostatics, Institute for Heath and Equity, Medical College of Wisconsin,

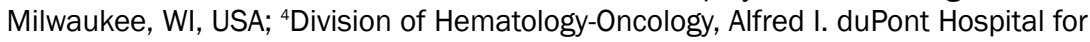
Children, Wilmington, DE, USA; ${ }^{5}$ Blood and Marrow Transplant Program, Icahn School of Medicine at Mount Sinai, New York, NY, USA; ${ }^{6}$ Center for International Blood and Marrow Transplant Research, National Marrow Donor Program/Be The Match, Minneapolis, MN, USA; 'Division of Hematology, Oncology and Blood \& Marrow Transplantation, Children's Hospital Los Angeles, University of Southern California Keck School of Medicine, Los Angeles, CA, USA; ${ }^{8}$ Division of Clinical Research, Department of Data Abstraction, Fred Hutchinson Cancer Research Center, Seattle, WA, USA; ' Division of Hematology-Oncology, University of Alabama at Birmingham, Birmingham, AL, USA; ${ }^{10}$ Division of Cancer Epidemiology \& Genetics, NIH-NCl Clinical Genetics Branch, Rockville, MD, USA ${ }^{11}$ Division of Hematology-Oncology, Rady Children's Hospital San Diego, San Diego, CA, USA; ${ }^{12}$ Division of Pediatric Hematology/Oncology, Department of Pediatrics, Washington University School of Medicine in St. Louis, St. Louis, MO, USA; ${ }^{13}$ Division of HematologyOncology, Children's Hospital and Research Center Oakland, Oakland, CA, USA; ${ }^{14}$ Division of Pediatric Hematology-Oncology, Tufts Medical Center, Boston, MA, USA; ${ }^{15} \mathrm{Blood}$ and Marrow Transplant Program, Department of Pediatrics, University of Minnesota, Minneapolis, MN, USA; ${ }^{16}$ Blood \& Marrow Transplant Program, Kids Cancer Center, Sydney Children's Hospital, Sydney, New South Wales, Australia; ${ }^{17}$ Blood and Cancer Center, Starship Children's Hospital, Auckland, New Zealand; ${ }^{18}$ Division of Bone and Marrow Transplantation and Cellular Therapy, St. Jude Children's Research Hospital, Memphis, TN, USA; ${ }^{19}$ The Children's Hospital at Westmead, Westmead, New South Wales, Australia; ${ }^{20}$ Division of Hematology-Oncology, Department of Pediatrics, Children's Hospital of Philadelphia, Philadelphia, PA, USA and ${ }^{21}$ Division of Hematology-Oncology, Department of Medicine, Medical College of Wisconsin, Milwaukee, WI, USA

\section{ABSTRACT}

W ith limited data comparing hematopoietic cell transplant outcomes between myeloablative total body irradiation (TBI) containing and non-TBI regimens in children with de novo acute myeloid leukemia, the aim of this study was to compare transplant-outcomes between these regimens. Cox regression models were used to compare transplant-outcomes after TBI and non-TBI regimens in 624 children transplanted between 2008 and 2016. Thirty two percent $(n=199)$ received TBI regimens whereas $68 \%(n=425)$ received non-TBI regimens. Five-year non-relapse mortality was higher with TBI regimens $(22 \%$ vs. $11 \%$, $P<0.0001)$ but relapse was lower $(23 \%$ vs. $37 \%, P<0.0001)$ compared to non-TBI regimens. Consequently, overall $(62 \%$ vs. $60 \%, P=1.00)$ and leukemia-free survival ( $55 \%$ vs. $52 \%, P=0.42)$ did not differ between treatment groups. Grade 2-3 acute graft versus host disease was higher with TBI regimens $(56 \%$ vs. $27 \%, P<0.0001)$ but not chronic graft versus host disease. The 3-year incidence of gonadal or growth hormone deficiency was higher with TBI regimens $(24 \%$ vs. $8 \%, P<0.001)$ but there were no differences in late pulmonary, cardiac or renal impairment. In the absence of a survival advantage, the choice of TBI or non-TBI regimen merits careful consideration with the data favoring non-TBI regimens to limit the burden of morbidity associated with endocrine dysfunction.
Haematologica 2021

Volume 106(7):1839-1845

Correspondence:

MARY EAPEN

meapen@mcw.edu

Received: February 6, 2020.

Accepted: June 12, 2020.

Pre-published: June 18, 2020.

https://doi.org/10.3324/haematol.2020.249458

(C)2021 Ferrata Storti Foundation

Material published in Haematologica is covered by copyright. All rights are reserved to the Ferrata Storti Foundation. Use of published material is allowed under the following terms and conditions:

https://creativecommons.org/licenses/by-nc/4.0/legalcode. Copies of published material are allowed for personal or internal use. Sharing published material for non-commercial purposes is subject to the following conditions:

https://creativecommons.org/licenses/by-nc/4.0/legalcode, sect. 3. Reproducing and sharing published material for commercial purposes is not allowed without permission in writing from the publisher. 


\section{Introduction}

Hematopoietic cell transplant (HCT) is accepted as the standard of care for children and adolescents with high risk or relapsed/refractory acute myeloid leukemia (AML).1.3 Total body irradiation (TBI) or busulfan $(\mathrm{Bu})$ containing myeloablative conditioning regimens are commonly used to treat these patients.,5 In 1992, a randomized trial in adults showed improved 2-year leukemia-free survival using conditioning with TBI-cyclophosphamide (Cy) compared to $\mathrm{Bu}$-Cy using oral busulfan formulation, which was available at that time, ${ }^{6}$ however, there are limited data in children and adolescents. Intravenous Bu has subsequently been developed, which provides more consistent pharmacokinetics and reliable dosing.? Further, pharmacokinetic targeting of intravenous Bu dosing reduces treatment-related toxicity. In the modern era, in adults, intravenous Buconditioning has been shown to be associated with improved non-relapse mortality, and overall and diseasefree survival in comparison to TBI-containing regimens.,10 However, acute graft versus host disease (GvHD), ${ }^{11}$ acute liver injury, ${ }^{12}$ pulmonary injury (e.g., diffuse alveolar hemorrhage), and bloodstream infections ${ }^{1,13,14}$ are reported to be higher with TBI-containing compared to non-TBI regimens. Late complications, including secondary malignancies, endocrine, metabolic, renal, ocular, and neurocognitive complications are also higher with TBI-containing compared to non-TBI myeloablative regimens. ${ }^{15-17}$ Although TBI-containing regimens are associated with significant toxicity in children, ${ }^{18}$ many physicians continue to use TBIcontaining regimens for transplantation for de novo AML in children and adolescents. In the absence of a randomized trial comparing TBI-containing versus non-TBI regimens in children, we utilized data on HCT reported to an observational registry, the Center for International Blood and Marrow Transplant Research (CIBMTR) to compare outcomes between the two treatment groups.

\section{Methods}

\section{Patients}

Data were reported prospectively to the CIBMTR, a voluntary working group of more than 450 transplant centers worldwide that contribute detailed data on allogeneic and autologous HCT. Participating centers report consecutive transplants and compliance is monitored by on-site audits. All patients are followed longitudinally until death or lost to follow-up. Eligible patients were aged $\leq 21$ years undergoing first allogeneic transplantation with myeloablative conditioning for de novo AML in first or second complete remission between 2008 and 2016 and consented for research. Excluded were patients with an antecedent hematologic disorder or secondary AML, mismatched related donor transplant and non-calcineurin inhibitor GvHD prophylaxis regimens. Patients were broadly grouped into TBI-containing (TBI$\mathrm{Cy}$ ), TBI-Cy-fludarabine (Flu) and non-TBI (Bu-Cy and Bu-Flu) regimens. The study was approved by the Institutional Review Board of the National Marrow Donor Program.

\section{Endpoint}

Grades 2-3 acute GvHD, grade 3-4 acute GvHD, and chronic GvHD were defined using standard definitions. ${ }^{1920}$ Relapse was defined as the recurrence of AML (morphologic, cytogenetic or molecular) and non-relapse mortality was defined as death in remission. Overall survival was defined where death from any cause was considered an event. Leukemia-free survival was defined as being alive in continuous remission. Neutrophil recovery was defined as achieving a count of $\geq 0.5 \times 10^{9} / \mathrm{L}$ for 3 consecutive days. Platelet recovery was defined as achieving a count of $\geq 20 \times 10^{9} / \mathrm{L}$ without transfusions for 7 consecutive days. The day100 incidence of veno-occlusive disease, systemic bacterial, viral and fungal infection were compared between the two treatment groups. The 5 -year incidence of post-transplant interstitial pneumonitis, congestive heart failure, gonadal dysfunction, growth hormone deficiency and renal failure severe enough to warrant dialysis were compared between the two treatment groups.

\section{Statistical methods}

Patient-related, disease-related, and transplant-related outcomes were compared between treatment groups using MannWhitney tests (continuous variables) and Fisher's exact/Chisquare test (categorical variables). A $P$-value of $<0.05$ was considered statistically significant. Cox regression models were built for acute and chronic GvHD, non-relapse mortality, relapse, overall and leukemia-free survival. ${ }^{21}$ The main effect (TBI-containing vs. non-TBI regimens) was forced in all models, and other covariates were retained in the final model if they met a significance level of less than 0.05 . Forward stepwise selection was used to identify significant covariates. The interaction between the main effect and significant covariates was examined. Assessment of the proportional-hazards assumption was done by examining the coefficient of the logarithm of time from transplant to the last followup for each covariate. The coefficients for the covariates which violated the proportional hazards assumption were added as time-varying effects. The adjusted survival or cumulative incidence probabilities were calculated based on the final Cox models. ${ }^{22,23}$ Center effects were tested for non-relapse mortality, relapse, overall and leukemia-free survival using the score test. ${ }^{24}$ All analyses were performed using SAS 9.4 (SAS Institute Inc, Cary, NC).

\section{Results}

\section{Patient, disease and transplant characteristics}

Six hundred and twenty-four patients transplanted at 124 transplant centers were eligible and their characteristics are shown in Table 1. TBI-containing regimens included TBI-Cy (38\%, 76 of 199) and TBI-Cy-Flu (62\%, 123 of 199). Non-TBI regimens included Bu-Cy (76\%, 322 of 425) and Bu-Flu (24\%, 103 of 425). Bu pharmacokinetics with dose adjustments were performed for $80 \%$ (338 of 425) of non-TBI transplantations. Patient and disease characteristics differed by treatment group. TBI-containing regimens were less likely to be used for children aged 3 years and younger, for transplants in first complete remission and more likely with umbilical cord blood $(67 \%)$. In very young children (age $\leq 3$ years, $n=170$ ), only $19 \%$ (33 of 170) received a TBI regimen. Bone marrow was the predominant graft for non-TBI regimen transplants (48\%). In vivo Tcell depletion with anti-thymocyte globulin was common with non-TBI regimens accounting for $52 \%$ of transplantations compared to only $11 \%$ with TBI-containing regimens. The predominant GvHD prophylaxis with TBI-containing regimens was cyclosporine with mycophenolate and for non-TBI regimen, tacrolimus or cyclosporine with methotrexate. There were no differences between treatment groups regarding performance score, hematopoietic co-morbidity index, sites at diagnosis and cytogenetic risk. Most transplant centers used both TBI-containing and non- 
TBI regimens $(n=57)$ or non-TBI regimens alone $(n=53)$. Only 14 centers used TBI-containing regimens alone. Further, between 2012 and 2016, only a third of transplants used TBI-containing regimens. Non-TBI regimens were equally likely to be used between 2008 and 2011 and between 2012 and 2016. The median follow-up of patients who received TBI-containing regimens was 63 months (range, 3-122 months) and for those who received non-TBI regimens, 50 months (range, 3-122 months).

Table 1. Patient, disease and transplant characteristics.

\begin{tabular}{|c|c|c|c|}
\hline Variable & |B]- regimens & Non-TBI regimens & P-value \\
\hline $\begin{array}{l}\text { Sex } \\
\quad \text { Male/female }\end{array}$ & $\begin{array}{c}101(51 \%) / \\
98(49 \%)\end{array}$ & $\begin{array}{l}217(51 \%) / \\
208(49 \%)\end{array}$ & 0.94 \\
\hline $\begin{array}{l}\text { Age } \\
\qquad 3 \text { years } \\
4-10 \text { years } \\
11-21 \text { years }\end{array}$ & $\begin{array}{c}33(17 \%) \\
49(25 \%) \\
117(59 \%)\end{array}$ & $\begin{array}{c}137(32 \%) \\
93(22 \%) \\
195(46 \%)\end{array}$ & $<0.001$ \\
\hline $\begin{array}{l}\text { Performance score } \\
90-100 \\
\leq 80 \\
\text { Not reported }\end{array}$ & $\begin{array}{l}168(84 \%) \\
26(13 \%) \\
5(3 \%)\end{array}$ & $\begin{array}{l}376(88 \%) \\
47(11 \%) \\
2(<1 \%)\end{array}$ & 0.06 \\
\hline $\begin{array}{l}\text { HCT co-morbidity index } \\
\quad \leq 2 \\
\geq 3 \\
\text { Not reported }\end{array}$ & $\begin{array}{l}172(86 \%) \\
25(13 \%) \\
2(1 \%)\end{array}$ & $\begin{array}{c}375(88 \%) \\
43(10 \%) \\
7(2 \%)\end{array}$ & 0.55 \\
\hline $\begin{array}{l}\text { Site (s) at diagnosis } \\
\text { Bone marrow only } \\
\text { Bone marrow + central } \\
\text { nervous system } \\
\text { Bone marrow + other sites } \\
\text { Not reported }\end{array}$ & $\begin{array}{l}132(66 \%) \\
52(26 \%) \\
12(6 \%) \\
3(2 \%)\end{array}$ & $\begin{array}{l}295(69 \%) \\
84(20 \%) \\
29(7 \%) \\
17(4 \%)\end{array}$ & 0.14 \\
\hline $\begin{array}{l}\text { Cytogenetic risk } \\
\text { Favorable } \\
\text { Intermediate } \\
\text { Poor } \\
\text { Not reported }\end{array}$ & $\begin{array}{c}29(15 \%) \\
123(62 \%) \\
41(21 \%) \\
6(3 \%)\end{array}$ & $\begin{array}{c}36(8 \%) \\
285(67 \%) \\
90(21 \%) \\
14(3 \%)\end{array}$ & 0.14 \\
\hline $\begin{array}{l}\text { Disease status at transplant } \\
1^{\text {st }} \text { complete remission } \\
2^{\text {nd }} \text { complete remission }\end{array}$ & $\begin{array}{l}107(54 \%) \\
92(46 \%)\end{array}$ & $\begin{array}{l}277(65 \%) \\
148(35 \%)\end{array}$ & 0.006 \\
\hline $\begin{array}{l}\text { Donor } \\
\text { HLA-matched sibling } \\
\text { HLA-matched unrelated donor } \\
\text { HLA-mismatched unrelated }\end{array}$ & $\begin{array}{l}17(9 \%) \\
34(17 \%) \\
14(7 \%)\end{array}$ & $\begin{array}{l}123(29 \%) \\
109(26 \%) \\
32(8 \%)\end{array}$ & \\
\hline $\begin{array}{l}\text { HLA-matched unrelated } \\
\text { cord blood } \\
\text { HLA-mismatched unrelated } \\
\text { cord blood } \\
\text { Unrelated cord blood } \\
\text { (not reported) }\end{array}$ & $\begin{array}{l}21(11 \%) \\
101(51 \%) \\
12(6 \%)\end{array}$ & $\begin{array}{l}29(7 \%) \\
99(23 \%) \\
33(8 \%)\end{array}$ & \\
\hline $\begin{array}{l}\text { Graft versus host disease prophylar } \\
\text { Tacrolimus + mycophenolate } \\
\text { Tacrolimus + methotrexate } \\
\text { Tacrolimus alone } \\
\text { Cyclosporine + mycophenolate } \\
\text { Cyclosporine + methotrexate } \\
\text { Cyclosporine alone` }\end{array}$ & $\begin{array}{l}\text { axis } \\
7(4 \%) \\
40(20 \%) \\
4(2 \%) \\
119(60 \%) \\
20(10 \%) \\
9(5 \%)\end{array}$ & $\begin{array}{c}42(10 \%) \\
139(33 \%) \\
8(2 \%) \\
77(18 \%) \\
115(27 \%) \\
44(10 \%\end{array}$ & $<0.001$ \\
\hline Anti-thymocyte globulin & $22(11 \%)$ & $221(52 \%)$ & $<0.001$ \\
\hline $\begin{array}{l}\text { Transplant period } \\
2008-2011 \\
2012-2016\end{array}$ & $\begin{array}{c}133(67 \%) \\
66(33 \%)\end{array}$ & $\begin{array}{l}192(45 \%) \\
233(55 \%)\end{array}$ & $<0.001$ \\
\hline
\end{tabular}

TBI: total body irradiation; HCT: hematopoietic cell transplant.

\section{Hematopoietic recovery}

The median time to neutrophil recovery was 20 days and 17 days after TBI-containing and non-TBI regimens, respectively $(P=0.04)$. The corresponding time to platelet recovery were 38 days and 30 days, $P=0.002$. Consequently, the day28 incidence of neutrophil recovery was lower after TBIcontaining (79\%, 95\% Confidence Interval [CI]: 73-84) compared to non-TBI regimens (85\%, 95\% CI: 82-88), $P=0.04$. Similarly, day-100 incidence of platelet recovery was also lower after TBI-containing (81\%, 95\% CI: 75-86) compared to non-TBI regimens (87\%, 95\% CI: 84-90), $P=0.002$.

\section{Acute and chronic graft versus host disease}

Grade 2-3 acute GvHD risk was higher with TBI-containing compared to non-TBI regimens (Table 2). The day-100 incidence of grade $2-3$ acute GvHD were $56 \%$ (95\% CI: 4963 ) and $27 \%$ (95\% CI: 22-30), respectively, $P<0.0001$. Compared to HLA-matched sibling donors, risks were higher with HLA-matched unrelated (hazard ratio [HR] 3.03 , 95\% CI: $1.75-5.25, P<0.0001)$, HLA-mismatched unrelated (HR 4.12, 95\% CI: 2.18-7.77, $P<0.0001$ ), HLAmatched cord blood (HR 3.02, 95\% CI: $1.44-6.34$, $P=0.0035$ ) and HLA-mismatched cord blood (HR 2.95, 95\% CI: $1.57-5.56, P=0.0008)$. Grade $3-4$ acute GvHD risk did not differ between the treatment groups (Table 2). Compared to bone marrow grafts, risk of acute GvHD was higher with peripheral blood (HR 3.22, 95\% CI: 1.72-6.03, $P=0.003$ ) and cord blood (HR 2.24, 95\% CI: 1.29-3.88, $P=0.0041)$. Chronic GvHD risk also did not differ between treatment groups (Table 2). The 5 -year incidence of chronic GvHD was 37\% (95\% CI: $30-44)$ and 30\% (95\% CI: $26-$ 35) after TBI-containing and non-TBI regimens. Chronic GvHD risks were higher in patients aged 11-21 years compared to those aged $\leq 3$ years (HR 1.78, 95\% CI: $1,13-2.81$,

Table 2. Results of multivariate analysis

\begin{tabular}{|c|c|c|c|}
\hline Outcome & $\begin{array}{l}\text { Events/ } \\
\text { Number }\end{array}$ & $\begin{array}{l}\text { Hazard Ratio } \\
\text { (95\% CI) }\end{array}$ & P-value \\
\hline $\begin{array}{l}\text { Grade } 2-4 \text { acute GvHD* } \\
\text { TBI-containing regimen } \\
\text { Non-TBI regimen }\end{array}$ & $\begin{array}{l}109 / 196 \\
112 / 420\end{array}$ & $\begin{array}{c}1.00 \\
0.44(0.33-0.58)\end{array}$ & $<0.0001$ \\
\hline $\begin{array}{l}\text { Grade } 3-4 \text { acute GvHD } \\
\text { TBI-containing regimen } \\
\text { Non-TBI regimen }\end{array}$ & $\begin{array}{l}34 / 196 \\
53 / 420\end{array}$ & $\begin{array}{c}1.00 \\
0.69(0.44-1.08)\end{array}$ & 0.10 \\
\hline $\begin{array}{l}\text { Chronic GvHD* } \\
\text { TBI-containing regimen } \\
\text { Non-TBI regimen }\end{array}$ & $\begin{array}{c}70 / 198 \\
116 / 422\end{array}$ & $\begin{array}{c}1.00 \\
0.82(0.59-1.13)\end{array}$ & 0.23 \\
\hline $\begin{array}{l}\text { Non-relapse mortality }^{\mid} \\
\text {TBI-containing regimen } \\
\text { Non-TBI regimen }\end{array}$ & $\begin{array}{l}42 / 199 \\
46 / 425\end{array}$ & $\begin{array}{c}1.00 \\
0.53(0.35-0.81)\end{array}$ & 0.003 \\
\hline $\begin{array}{l}\text { Relapse }^{\sharp} \\
\text { TBI-containing regimen } \\
\text { Non-TBI regimen }\end{array}$ & $\begin{array}{c}43 / 199 \\
149 / 425\end{array}$ & $\begin{array}{c}1.00 \\
1.46(1.04-2.07)\end{array}$ & 0.03 \\
\hline $\begin{array}{l}\text { Leukemia-free survival }^{* *} \\
\text { TBI-containing regimen } \\
\text { Non-TBI regimen }\end{array}$ & $\begin{array}{c}85 / 199 \\
195 / 425\end{array}$ & $\begin{array}{c}1.00 \\
1.01(0.78-1.31)\end{array}$ & 0.95 \\
\hline $\begin{array}{l}\text { Overall survival }^{\mid} \\
\text {TBI-containing regimen } \\
\text { Non-TBI regimen }\end{array}$ & $\begin{array}{c}73 / 199 \\
159 / 425\end{array}$ & $\begin{array}{c}1.00 \\
0.98(0.74-1.30)\end{array}$ & 0.91 \\
\hline
\end{tabular}

GvHD: graft versus host disease; TBI. total body irradiation: CI: Confidence Interval; TBI: total body irradiation; *adjusted for age, donor type and GvHD prophylaxis; | adjusted for age; *adjusted for age and site(s) at diagnosis and **adjusted for age and cytogenetic risk. 
$P=0.01)$ and $4-10$ years (HR 2.29, 95\% CI: 1.57-3.33, $P<0.0001)$. Chronic GvHD was higher with HLA-mismatched cord blood compared to HLA-matched sibling donors (HR 2.04, 95\% CI: 1.10-3.67, $P=0.02$ ). Chronic GvHD risks did not differ between other donor groups (data not shown).

\section{Non-relapse mortality and relapse}

Non-relapse mortality was higher with TBI-containing regimens (Table 2, Figure 1A). The 1- and 5-year incidence of non-relapse mortality with TBI-containing regimens were $17 \%$ (95\% CI: $12-22)$ and $22 \%$ (95\% CI: 16-28). The corresponding incidence with non-TBI regimens were $8 \%$ (95\% CI: 6-11) and 11\% (95\% CI: 8-15). Compared to patients aged 4-10 years, non-relapse mortality was higher in patients aged $11-21$ years (HR 1.99, 95\% CI: 1.15-3.46, $P=0.01)$ but not in those aged $\leq 3$ years (HR 1.71, 95\% CI: $0.85-3.44, P=0.13)$. Infections were higher with TBI-containing compared to non-TBI regimens (Table 3A). Venoocclusive disease was lower with TBI-containing regimens (Table 3A). Patients who survived at least 1 year after transplantation in remission were evaluable for organ dysfunction (Table 3B). Endocrine dysfunction (thyroid or gonadal) was higher with TBI-containing regimens. Pulmonary, cardiac and renal complications did not differ between treatment groups.

Relapse risks were lower in TBI-containing regimens (Table 2, Figure 1B). The 1- and 5-year incidence of relapse with TBI-containing regimens were $15 \%$ (95\% CI: 11-22) and $23 \%$ (95\% CI: 17-29). The corresponding relapse incidence with non-TBI regimens were $26 \%$ (95\% CI: 22-31) and $37 \%$ (95\% CI: 32-42), $P<0.0001$. Relapse risks did not differ between patients aged 4-10 and 11-21 years (HR 1.17, 95\% CI: 0.82-1.69, $P=0.39)$. Relapse was higher in patients aged $\leq 3$ years compared to those aged $4-10$ years (HR 2.49, 95\% CI: $1.68-3.69, P<0.0001)$ and $11-21$ years (HR 2.12, $95 \%$ CI: $1.51-2.98, P<0.0001)$. Compared to bone marrow and central nervous system involvement at diagnosis,

A

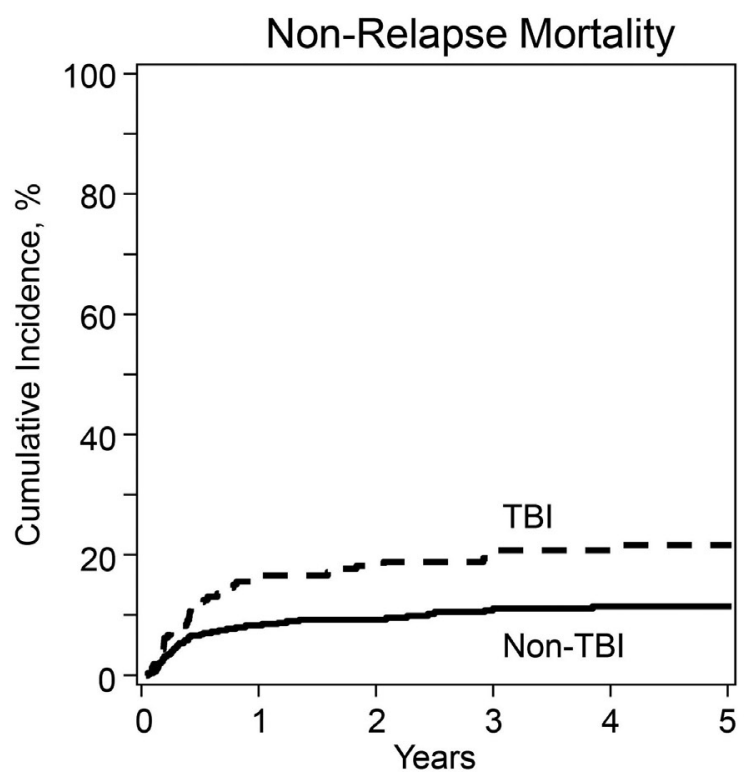

relapse risks were higher in patients with bone marrow involvement alone (HR 1.93, 95\% CI: 1.27-2.93, $P=0.002$ ) and bone marrow with extramedullary site(s) excluding central nervous system involvement ( $\mathrm{HR} 1.88$, 95\% CI: $1.01-3.50, P=0.04)$. Acute grade $2-4 \mathrm{GvHD}$ was associated with lower relapse risk (HR 0.63, 95\% CI: 0.44-0.89, $P=0.008)$ but this was independent of conditioning regimen. The effect of acute grade 3-4 (HR 0.65, 95\% CI: 0.39 1.09, $P=0.10$ ) and chronic GvHD (HR 0.74, 95\% CI: 0.48 $1.15, P=0.19)$ on relapse did not meet the level of significance that was set a priori.

\section{Overall and leukemia-free survival}

There were no differences in overall or leukemia-free survival by treatment groups (Table 2, Figure $2 \mathrm{~A}$ and $\mathrm{B}$ ). Age was associated with both overall and leukemia-free survival and cytogenetic risk with leukemia-free survival. Compared to patients aged 4-10 years, survival was lower for those aged $11-21$ years (HR 1.82, 95\% CI: 1.28-2.59, $P<0.0001)$ and $\leq 3$ years (HR 2.79, 95\% CI: 1.90-4.10, $P<0.0001)$. Survival was also lower in patients aged $\leq 3$ years compared to those aged 11-21 years (HR 1.52, 95\% CI: 1.14-2.08, $P=0.005)$. Compared to favorable cytogenetics, leukemia-free survival was lower with intermediate risk (HR 1.85, 95\% CI: 1.10-3.09, $P=0.0198$ ) and poor risk (HR 2.46 , 95\% CI: $1.42-4.27, P=0.0013)$. The 5 -year overall survival was $61 \%$ (95\% CI: 54-68) and 61\% (95\% CI: 56-66) after TBI-containing and non-TBI containing regimens. The corresponding leukemia-free survival was $53 \%$ (95\% CI: $46-60)$ and 53\% (95\% CI: 48-58).

\section{Transplant period}

As the current analysis included patients transplanted between 2008 and 2016, we tested for an effect of transplant period (2012-2016 vs. 2008-2011) on non-relapse mortality (HR 0.75, 95\% CI $0.48-21.17, P=0.21)$, relapse (HR 1.04, 95\% CI: $0.78-1.41, P=0.78$ ), overall (HR 0.93, 95\% CI: $0.71-1.22, P=0.62)$ and leukemia-free survival (HR 0.96,

B

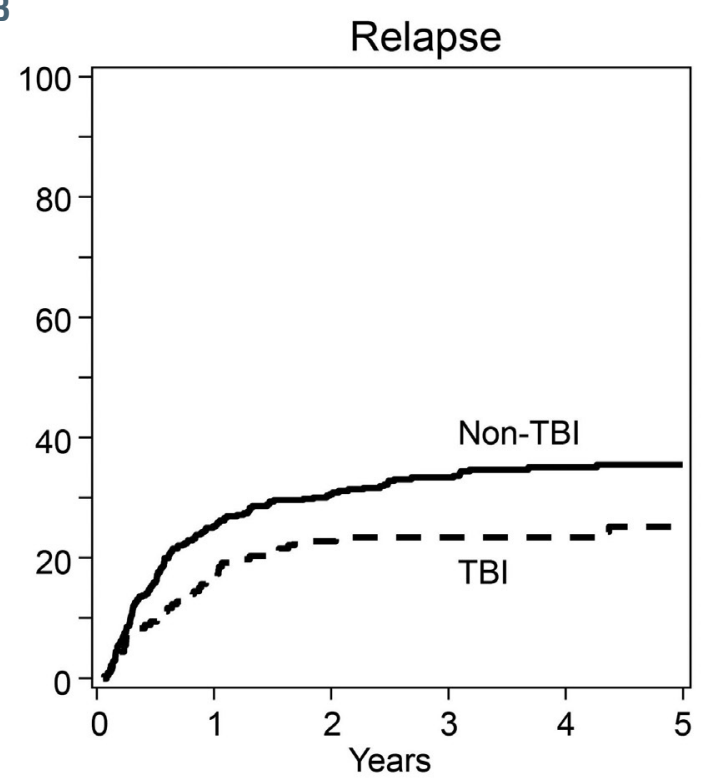

Figure 1. Non-relapse mortality and relapse. (A) Cumulative incidence of non-relapse mortality with total body irradiation (TBI)-containing and non-TBI regimens, (B) cumulative incidence of relapse with TBI-containing and non-TBI regimens. 
95\% CI: $0.75-1.23, P=0.15)$ and found none. We also examined for differences in infection rates by transplant period and observed lower rate of fungal infection between 2012 and 2016 compared to the earlier period in patients who received TBI-containing ( $2 \%$ vs. $8 \%$ ) and non-TBI (1\% vs. $4 \%$ ) regimens.

\section{Subset analysis}

In a subset analysis limited to patients who received Bu$\mathrm{Cy}$ and Bu-Flu, we examined for an effect of anti-thymocyte globulin on grade 2-4 acute GvHD (HR 0.68, 95\% CI: $0.44-1.03, P=0.07$ ), grade $3-4$ acute GvHD (HR 0.93, 95\% CI: 0.51-1.70, $P=0.82$ ), chronic GvHD (HR 0.75, 95\% CI:
0.50-1.12, $P=0.16$ ), non-relapse mortality (HR 1.09, 95\% CI: $0.60-1.99, P=0.78)$, relapse (HR 1.07, 95\% CI: 0.77-1.50, $P=0.68$ ), overall (HR 1.24, 95\% CI: $0.90-1.72, P=0.19)$ and leukemia-free survival (HR 1.05, 95\% CI: 0.78-1.40, $P=0.75)$ and found none.

\section{Discussion}

To our knowledge this is the largest study to compare $\mathrm{TBI}$ and non-TBI intravenous Bu containing regimens in children and adolescents with de novo AML. Non-relapse mortality was higher with TBI regimens, and relapse was

Table 3A. Day-100 incidence of veno-occlusive disease and systemic infection.

\begin{tabular}{|c|c|c|c|c|c|}
\hline \multirow[b]{2}{*}{ Outcome } & \multicolumn{2}{|c|}{ TBI-containing regimen } & \multicolumn{2}{|c|}{ Non-TBI regimen } & \multirow[b]{2}{*}{ P-value } \\
\hline & N eval & Probability (95\% CI) & N eval & Probability (95\% CI) & \\
\hline VOD & 197 & $8 \%(4-12)$ & 422 & $15 \%(11-18)$ & 0.03 \\
\hline Bacterial bloodstream infection & 199 & $47 \%(40-54)$ & 425 & $30 \%(26-35)$ & $<0.001$ \\
\hline Viral bloodstream infection & 199 & $43 \%(36-50)$ & 425 & $30 \%(26-34)$ & 0.001 \\
\hline Fungal bloodstream infection & 199 & $6 \%(3-9)$ & 425 & $2 \%(1-4)$ & 0.04 \\
\hline
\end{tabular}

TBI: total body irradiation;VOD: veno-occlusive disease; CI: Confidence Interval; eval: evaluated.

Table 3B. 3-year incidence of organ dysfunction in patients who were alive and in remission for at least 1-year post-transplant

\begin{tabular}{|c|c|c|c|c|c|}
\hline \multirow[b]{2}{*}{ Outcome } & \multicolumn{2}{|c|}{ (1B)-containing regimen } & \multicolumn{2}{|c|}{ Non-IBI regimen } & \multirow[b]{2}{*}{ P-value } \\
\hline & N eval & Probability (95\% CI) & $\mathrm{N}$ eval & Probability (95\% CI) & \\
\hline $\begin{array}{l}\text { Interstitial pneumonitis / Idiopathic } \\
\text { pneumonia syndrome }\end{array}$ & 129 & $5 \%(2-9)$ & 267 & $7 \%(4-11)$ & 0.36 \\
\hline $\begin{array}{l}\text { Endocrine dysfunction (gonadal } \\
\text { or growth hormone) }\end{array}$ & 125 & $24 \%(17-32)$ & 265 & $8 \%(5-12)$ & $<0.001$ \\
\hline $\begin{array}{l}\text { Cardiac failure, renal failure } \\
\text { requiring dialysis }\end{array}$ & 129 & $5 \%(2-9)$ & 267 & $3 \%(1-5)$ & 0.26 \\
\hline
\end{tabular}

Number of events: gonadal dysfunction TBI $n=28$ of 125 ; non-TBI $n=29$ of 265 ; growth hormone deficiency TBI $n=14$ of 129 , non-TBI n=7 of 265 ; cardiac failure TBI n=3 of 129 , non-TBI $n=1$ of 267 ; renal failure TBI $n=4$ of 129 , non-TBI $N=7$ of 267 .TBI: total body irradiation; CI: Confidence Interval; n: number; eval: evaluated.

A

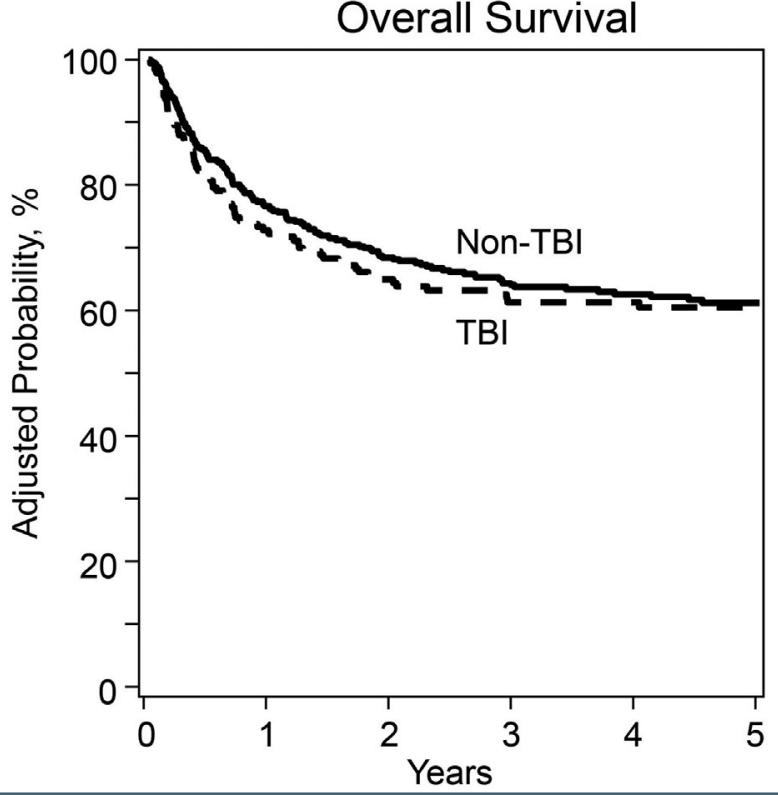

B
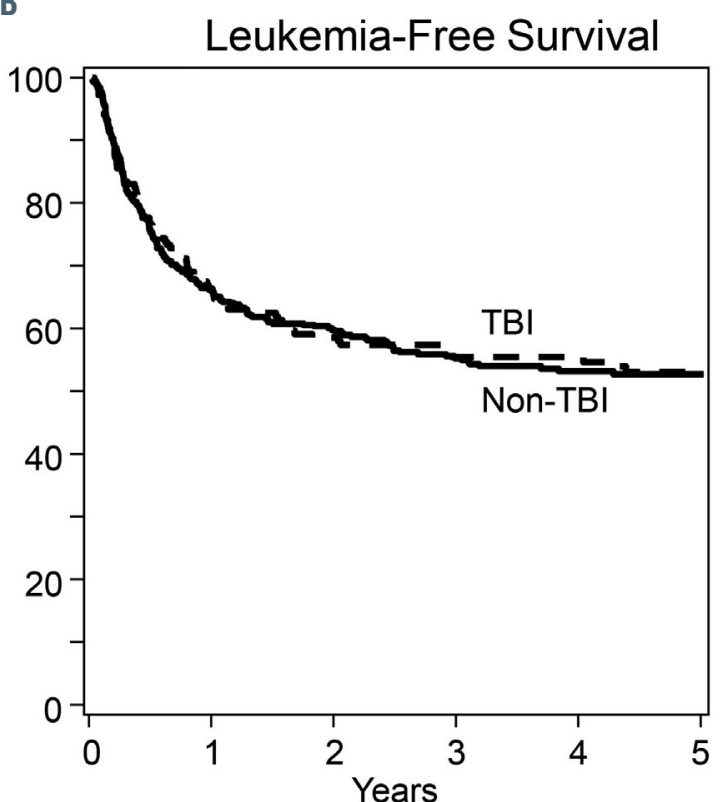

Figure 2. Leukemia-free survival and overall survival. (A) Probability of overall survival with total body irradiation (TBI)-containing and non-TBI regimens, (B) probability of leukemia-free survival with TBI-containing and non-TBI regimens. 
higher with non-TBI regimens, negating an advantage for overall or leukemia-free survival. The net contribution of non-relapse mortality or relapse for either treatment group was not sufficient to lead towards an overall or leukemia-free survival advantage. Our findings are in keeping with another pediatric study from Japan that also failed to show differences in overall and leukemia-free survival between TBI-containing and non-TBI Bu regimens. ${ }^{1}$ We hypothesize there are several factors that influenced relapse risks including acute grade 2-4 GvHD. TBI regimens were largely used with cord blood transplants and TBI-Cy-Flu was the predominant regimen. Others have reported lower relapse with TBI-Cy-Flu regimen compared to other TBI- and non-TBI containing regimens for cord blood transplant. ${ }^{25}$ The higher incidence of bacterial, viral and fungal infections with the TBI-containing regimens within the first 3 months after transplantation likely contributed to early transplant-related mortality. Whether this is an effect of the conditioning regimen or the type of donor is challenging to differentiate as TBI regimens were predominantly used for cord blood transplants. In the subset, limited to transplants between 2012 and 2016, the incidence of bacterial and viral infections was also higher with TBI-regimens and consistent with the main analysis. However, the incidence of invasive fungal infection decreased to $2 \%$ with TBI regimens and $1 \%$ with non-TBI regimens for transplants between 2012 and $2016(P=0.89)$ although this had negligible effect on non-relapse mortality (HR 1.18, $P=0.72$ ). A higher 5 -year overall survival recorded with TBI-Cy-Flu compared to non-TBI regimens may be acceptable for some considering cord blood transplant even though growth hormone and gonadal deficiency is higher with TBI-Cy-Flu regimen. ${ }^{25}$ For transplantations with HLA-matched sibling or adult unrelated donors intravenous Bu-Cy or Bu-Flu is preferred. ${ }^{26,27}$ A recent study from the European Society for Blood and Marrow Transplant (EBMT) observed lower relapse and higher leukemia-free survival for AML in first complete remission with Bu-Cy-melphalan compared to Bu-Cy and TBI-Cy. ${ }^{28}$ Our study did not include the Bu-Cy-melphalan regimen.

Hematopoietic recovery was lower with TBI-containing regimens. We hypothesize the lower recovery rates are in part explained by the predominant use of umbilical cord blood graft with TBI-containing regimens and in part, by use of intravenous $\mathrm{Bu}$ for all patients and pharmacokinetic data available for $80 \%$ of patients in the non-TBI group. Higher neutrophil but not platelet recovery with intravenous $\mathrm{Bu}$ containing regimens compared to TBI-containing regimens has been reported in adults with acute leukemia. ${ }^{10}$

Consistent with other reports, TBI-containing regimens were associated with higher incidence of thyroid and growth hormone deficiency compared to non-TBI regimens. ${ }^{21,22}$ Although not studied in the current analysis, others have recorded higher risk of cataracts, neuropsychological and cognitive abnormalities with TBI-containing regimens. ${ }^{22-24}$ The 5-year incidence of cardiac failure and renal failure were modest $(<10 \%)$ but did not differ between treatment groups. Although not the focus of the current study, two recent publications studied the association between myeloablative conditioning regimens and second neoplasm. Those reports did not record a higher risk with TBI-containing compared to non-TBI regimens. ${ }^{27,29}$
There are limitations to studying the effect of transplant conditioning regimen in a retrospective cohort. First, we do not know the factors that influenced choice of conditioning regimen other than in the youngest age group ( $\leq 3$ years), approximately $70 \%$ of those who received TBI regimen were in second complete remission. Although we performed a carefully controlled analyses there may be unknown or unmeasured factors that may have influenced the outcomes recorded. Second, over the course of the study, effective molecular flow cytometric measures of detectable disease in patients in complete remission at transplantation may have helped refine prognosis after transplantation ${ }^{30}$ although it can be argued that the effect of minimal residual disease (MRD) would be consistent across both treatment groups. Among 166 patients for whom MRD status was available, 6 of 33 $(18 \%)$ patients who received TBI and 17 of $133(13 \%)$ patients who received non-TBI regimens were MRD negative at transplantation. Third, we know most patients who received $\mathrm{Bu}$ had pharmacokinetic dose adjustments, but we do not have data on dose adjustments to examine whether an increase or decrease to the prescribed Bu dose was associated with outcomes. Our study spanned a 9year period, a strength considering our sample size, but leukemia-free and overall survival may be influenced by transplant period. A careful analysis failed to find an effect of transplant period on outcomes other than a lower incidence of invasive fungal infection with TBI regimens.

Our findings are relevant regarding a discussion on the choice of TBI-containing or non-TBI regimen when considering allogeneic transplantation for children and adolescents with de novo AML. In the absence of a survival advantage with either regimen group, the non-TBI regimens, Bu-Cy or $\mathrm{Flu}-\mathrm{Bu}$, are preferred although when considering umbilical cord blood transplantation TBI-Cy-Flu may be preferred. ${ }^{25}$

\section{Disclosures}

No conflicts of interest to disclose.

\section{Contributions}

$C E D, S M D, K W A, A E K$, JL and ME designed the study; SB$S$ prepared the study file, KWA and YH analyzed the data; CED, $S M D, K W A, Y H$ and ME interpreted the results; CED drafted the manuscript; SMD, KWA, YH, AEK, JL, SB-S, HA-A, NB, $J C, S G, N G, R H, N R L, J L, M M, T O, T P, A S, P S, L W$ and $M E$ critically reviewed and edited the manuscript; all authors approved the final version.

\section{Funding}

The CIBMTR is supported primarily by Public Health Service Grant/Cooperative Agreement 5U24-CA076518 from the National Cancer Institute (NCI), the National Heart, Lung and Blood Institute (NHLBI) and the National Institute of Allergy and Infectious Diseases (NIAID); 5U10HL069294 from NHLBI and NCI; a contract HHSH250201200016C with Health Resources and Services Administration (HRSA/DHHS); grants N0001415-1-0848 and N00014-16-1-2020 from the Office of Naval Research. The views expressed in this article do not reflect the official policy or position of the National Institute of Health, the Department of the Navy, the Department of Defense, Health Resources and Services Administration (HRSA) or any other agency of the U.S. Government. 


\section{References}

1. Ishida $H$, Kato $M$, Kudo $K$, et al. Comparison of outcomes for pediatric patients with acute myeloid leukemia in remission and undergoing allogeneic hematopoietic cell transplantation with myeloablative conditioning regimens based on either intravenous busulfan or total body irradiation: a report from the Japanese Society for Hematopoietic Cell Transplantation. Biol Blood Marrow Transplant. 2015;21(12):2141-2147.

2. Kinnunen U, Koistinen P, Ohtonen P, et al. Influence of chemotherapy courses on the rate of bloodstream infections during neutropenia in adult acute myeloid leukaemia. Scand J Infect Dis. 2008;40(8):642-647.

3. Rubnitz JE. How I treat pediatric acute myeloid leukemia. Blood. 2012;119(25): 5980-5988.

4. Socié G, Clift RA, Blaise D, et al. Busulfan plus cyclophosphamide compared with total-body irradiation plus cyclophosphamide before marrow transplantation for myeloid leukemia: long-term follow-up of 4 randomized studies. Blood. 2001;98(13): 3569-3574.

5. Thomas ED, Buckner CD, Banaji M, et al. One hundred patients with acute leukemia treated by chemotherapy, total body irradiation, and allogeneic marrow transplantation. Blood. 1977;49(4):511-533.

6. Blaise D, Maraninchi D, Archimbaud E, et al. Allogeneic bone marrow transplantation for acute myeloid leukemia in first remission: a randomized trial of a busulfanCytoxan versus Cytoxan-total body irradiation as preparative regimen: a report from the Group d'Etudes de la Greffe de Moelle Osseuse. Blood. 1992;79(10):2578-2582.

7. Andersson BS, Kashyap A, Gian V, et al. Conditioning therapy with intravenous busulfan and cyclophosphamide (IV BuCy2) for hematologic malignancies prior to allogeneic stem cell transplantation: a phase II study. Biol Blood Marrow Transplant. 2002;8(3):145-154.

8. Pidala J, Kim J, Anasetti C, et al Pharmacokinetic targeting of intravenous busulfan reduces conditioning regimen related toxicity following allogeneic hematopoietic cell transplantation for acute myelogenous leukemia. J Hematol Oncol. 2010:3:36.

9. Copelan EA, Hamilton BK, Avalos B, et al. Better leukemia-free and overall survival in AML in first remission following cyclophosphamide in combination with busulfan compared with TBI. Blood. 2013;122(24): 3863-3870.

10. Bredeson C, LeRademacher J, Kato K, et al Prospective cohort study comparing intravenous busulfan to total body irradiation in hematopoietic cell transplantation. Blood. 2013;122(24):3871-3878.

11. Nakasone H, Fukuda T, Kanda J, et al. Impact of conditioning intensity and $\mathrm{TBI}$ on acute GVHD after hematopoietic cell transplantation. Bone Marrow Transplant. 2015;50(4):559-565

12. Radhakrishnan K, Bishop J, Jin Z, et al. Risk factors associated with liver injury and impact of liver injury on transplantationrelated mortality in pediatric recipients of allogeneic hematopoietic stem cell transplantation. Biol Blood Marrow Transplant. 2013;19(6):912-917.

13. Ustun C, Young JH, Papanicolaou GA, et al. Bacterial blood stream infections (BSIs), particularly post-engraftment BSIs, are associated with increased mortality after allogeneic hematopoietic cell transplantation. Bone Marrow Transplant. 2019;54:1254-1265.

14. Dandoy CE, Ardura MI, Papanicolaou GA, et al. Bacterial bloodstream infections in the allogeneic hematopoietic cell transplant patient: new considerations for a persistent nemesis. Bone Marrow Transplant. 2017;52(8):1091-1106.

15. Freycon F, Casagranda L, Trombert-Paviot B. The impact of severe late-effects after $12 \mathrm{~Gy}$ fractionated total body irradiation and allogeneic stem cell transplantation for childhood leukemia (1988-2010). Pediatr Hematol Oncol. 2019;36(16):86-102.

16. Bresters D, Lawitschka A, Cugno C, et al. Incidence and severity of crucial late effects after allogeneic HSCT for malignancy under the age of 3 years: TBI is what really matters. Bone Marrow Transplant. 2016;51(11): 1482-1489.

17. Faraci M, Barra S, Cohen A, et al. Very late nonfatal consequences of fractionated TBI in children undergoing bone marrow transplant. Int J Radiat Oncol Biol Phys. 2005;63 (5):1568-1575.

18. Bhatia S, Davies SM, Scott Baker K, et al. $\mathrm{NCI}$, NHLBI first international consensus conference on late effects after pediatric hematopoietic cell transplantation: etiology and pathogenesis of late effects after HCT performed in childhood--methodologic challenges. Biol Blood Marrow Transplant. 2011;17(10):1428-1435

19. Przepiorka D, Weisdorf D, Martin P, et al. 1994 Consensus Conference on Acute GVHD Grading. Bone Marrow Transplant. 1995;15(6):825-828.
20. Lee SJ, Klein JP, Barrett AJ, et al. Severity of chronic graft-versus-host disease: association with treatment-related mortality and relapse. Blood. 2002;100(2):406-414.

21. Klein KP and Moeschberger ML. Survival analysis. techniques for censored and truncated data. Springer Science \& Business Media. 2006

22. Zhang X, Zhang MJ. SAS macros for estimation of direct adjusted cumulative Incidence curves under proportional subdistribution hazards models. Comput Methods Programs Biomed. 2011;101(1):87-93.

23. Zhang X, Loberiza FR, Klein JP, Zhang MJ. A SAS macro for estimation of direct adjusted survival curves based on a stratified Cox regression model. Comput Methods Programs Biomed . 2007;88(2):95-101.

24. Commenges D, Andersen PK. Score test of homogeneity for survival data. Lifetime Data Anal. 1995;1(2):145-156.

25. Eapen M, Kurtzberg J, Zhang MJ, et al Umbilical cord blood transplantation in children with acute leukemia: impact of conditioning on transplantation outcomes. Bio Blood Marrow Transplant. 2017;23(10): 1714-1721

26. Wilhelmsson M, Vatanen A, Borgström B, et al. Adverse health events and late mortality after pediatric allogeneic hematopoietic SCT-two decades of longitudinal follow-up. Bone Marrow Transplant. 2015;50(6):850857.

27. Vrooman LM, Millard HR, Brazauskas R, et al. Survival and late effects after allogeneic hematopoietic cell transplantation for hematologic malignancy at less than three years of age. Biol Blood Marrow Transplant. 2017;23(8):1327-1334.

28. Lucchini G, Labopin M, Beohou E, et al. Impact of conditioning regimen on outcomes for children with acute myeloid leukemia undergoing transplantation in first complete remission. An analysis on behalf of the Pediatric Disease Working Party of the European Group for Blood and Marrow Transplant. Biol Blood Marrow Transplant. 2017;23(3):467-474

29. Lee CJ, Kim S, Tecca HR, et al. Late effects after ablative stem cell transplantation for adolescents and young adults with acute myeloid leukemia. Blood Adv. 2020;4(6) 983-992.

30. Araki D, Wood BL, Othus $\mathrm{M}$, et al Allogeneic hematopoietic cell transplantation for acute myeloid leukemia: time to move toward a minimal residual diseasebased definition of complete remission? Clin Oncol. 2016;34(4):329-336. 